\title{
Allan, Châteauneuf-du-Rhône, Espeluche
}

Gazoduc

Christine Ronco

\section{(2) OpenEdition}

Édition électronique

URL : http://journals.openedition.org/adlfi/7088

ISSN : 2114-0502

Éditeur

Ministère de la culture

Référence électronique

Christine Ronco, "Allan, Châteauneuf-du-Rhône, Espeluche », ADLFI. Archéologie de la France-

Informations [En ligne], Rhône-Alpes, mis en ligne le 01 mars 2007, consulté le 03 mai 2019. URL

http://journals.openedition.org/adlfi/7088

Ce document a été généré automatiquement le 3 mai 2019.

(C) Ministère de la Culture et de la Communication, CNRS 


\section{Allan, Châteauneuf-du-Rhône, Espeluche}

Gazoduc

Christine Ronco

Identifiant de l'opération archéologique : 229455

Date de l'opération : 2007 (EX)

1 Trois secteurs du tracé du gazoduc entre Porte-en-Valdaine et Châteauneuf-du-Rhône ont fait l'objet d'une opération de diagnostic par sondages représentant une zone de près de $10 \mathrm{~km}$.

2 Outre quelques fossés historiques dont l'orientation n'a pu être définie et quelques drains modernes, les sondages ont permis la découverte de deux structures en place: dans la tranchée 80 (Espeluche, parcelle ZE 97), un fond de cuvette charbonneuse associé à de la céramique du Bronze final ou du début du premier âge du Fer; dans le sondage 107 (Châteauneuf-du-Rhône, parcelle ZE 36), une fosse (ST 107-5) datée par le mobilier qu'elle contenait du Bronze final IIb ou du début du Bronze final IIIa. Dans le sondage 95 (Allan, parcelle ZV 12) la présence de céramique et de matériel lithique néolithique (US 95-2), d'un chopper en quartzite et d'un débitage laminaire attribués sous réserve au Paléolithique moyen et/ou supérieur, témoignent de la présence de sites colluviés à proximité. L'intérêt de ce diagnostic a surtout porté sur l'étude géomorphologique menée par Jacques-Léopold Brochier (CAP de Valence) en complément de ses travaux antérieurs sur ce secteur.

RONCO Christine 
INDEX

operation expertise (EX)

Index chronologique : Âge du Fer, Bronze final, Paléolithique moyen, Paléolithique supérieur Index géographique : Rhône-Alpes, Drôme, Allan, Châteauneuf-du-Rhône, Espeluche

AUTEURS

CHRISTINE RONCO 